\title{
A TRADUÇÃO DA PARTÍCULA MODAL WOHL PARA O PORTUGUÊS: UMA INVESTIGAÇÃO DO ESFORÇO DE PROCESSAMENTO DE PARTICIPANTES BRASILEIROS E ALEMÃES
}

\author{
Marceli Aquino 1 \\ 1Universidade de São Paulo, São Paulo, São Paulo, Brasil
}

Resumo: Tendo como base a Teoria da Relevância, propomos investigar o esforço de processamento da partícula modal (doravante PM) wohl no par linguístico alemão/português em tarefas de pós-edição (doravante $\mathrm{PE}$ ). Nesse sentido, foram utilizados três instrumentos de pesquisa: o programa Translog-II; o rastreador ocular Tobii T60; relatos retrospectivos (livre e guiado). Dezesseis participantes, entre eles oito brasileiros e oito alemães, pós-editaram para o português três insumos da máquina em alemão contendo a PM wohl em três diferentes posições na mesma oração. Os resultados corroboram a suposição de GUTT (1998) e os resultados da análise processual conduzida por ALVES (2007), que revelam que a relação entre esforço e efeito não acontece com base em uma associação de proporção direta. Neste sentido, a análise do processamento de dois grupos de participantes com relação à da PM wohl demonstra que, em ambientes cognitivos diferenciados, a capacidade de metarrepresentação tem implicações distintas na busca de determinados efeitos contextuais.

Palavras-chave: Partículas modais alemãs; Abordagem processual em tradução; Teoria da relevância 


\title{
THE TRANSLATION OF THE MODAL PARTICLE WOHL INTO PORTUGUESE: AN INVESTIGATION OF THE PROCESSING EFFORT OF BRAZILIANS AND GERMANS PARTICIPANTS
}

\begin{abstract}
Using the Relevance Theory as guideline we investigate the processing effort of the modal particle (MP) wohl in the linguistic pair german/portuguese in post-editing tasks. As experimental background, we use three distinct research tools: the program Translog-II; the eyetracker Tobii T60; retrospective reports (free and guided). Sixteen participants, eight Brazilian and eight German, post-edited to Portuguese three machine translation inputs in German containing the MP wohl in three different positions related to the same sentence. The results here presented tend to confirm the hypothesis by GUTT (1998) and the study on processing analysis performed by ALVES (2007), which show that the relation between effort and effect does not obey a linear relation among themselves. Therefore, the analysis of how modal particles are processed in post-editing tasks tends to show that different cognitive environments imply distinct allocation of the minimum cognitive effort needed to achieve a relevant contextual effect.
\end{abstract}

Keywords: German modal particles; Procedural approach in translation; Relevance theory

\section{Introdução}

A partícula modal (doravante PM) wohl tem a função principal de caracterizar uma incerteza por parte do emissor, que cuidadosamente coloca sua suposição (HELBIG, 1990, p. 115). Assim, ela tem a intenção de manifestar uma pressuposição ou hipótese, que dá margens ao desenvolvimento da troca comunicativa. Os resultados apresentados nas investigações focadas nesta PM (THURMAIR, 1989; ABRAHAM, 1991a, 2012a; ZIMMERMANN, 2004, 2008) indicam que, com wohl o emissor expressa uma suposição, um tipo de afirmação especulativa, na qual o emissor não está totalmente comprometido com a verdade da proposição. 
A PM wohl, assim como as demais PMs, é descrita como um marcador lexical contextual, com a função principal de relacionar o enunciado à uma informação particular, isto é, considerando as intenções e expectativas dos interlocutores, e como estas são acessadas na busca de sentido. Leiss (2012, p. 44) qualifica as PMs como técnicas para proporcionar uma ligação especial entre o enunciado, o contexto e o conhecimento mutuamente manifestado entre o emissor e o receptor. Essa relação é guiada pela troca de informações relevantes, isto é, a informação que acarrete o maior acréscimo de conhecimento com o menor custo de processamento (SPERBER; WILSON, 2005, p. 227).

No sentido de acessar o significado das PMs, se faz necessário uma investigação contextual profunda, tendo em conta o aspecto interpessoal, isto é, a intenção e expectativa do emissor e do receptor. Além da análise inferencial dentro do contexto de uso, se faz necessário refletir sobre as funções nucleares específicas de cada $\mathrm{PM}^{1}$ (AQUINO, 2017, p. 157). Assim, estes elementos lexicais devem ser descritos levando em consideração a sua função nuclear, o contexto, a sua intenção comunicativa e o seu significado com relação aos outros elementos da oração. Logo, para alcançar uma melhor compreensão sobre o funcionamento geral das PMs gramatical, semanticamente e sua importância como meio comunicativo, é preciso analisá-las sob os aspectos sintáticos, semânticos e pragmáticos.

Para orientar a análise, como também a tradução das PMs, encontra-se na literatura alguns parâmetros que facilitam e delimitam a identificação destes elementos no discurso, como a restrição de seu status topológico (ABRAHAM 1991b, p. 331). As PMs podem aparecer apenas em extensões sintáticas determinadas, ou seja, no Mittelfeld ou campo central ${ }^{2}$. A divisão por campos (feld) é uma característica da língua alemã e advém da separação da ora-

${ }^{1}$ A PM doch, por exemplo, tem a função de indicar contradição a respeito de alguma situação ou informação. Já a PM wohl tem a função de sinalizar uma hipótese ou a falta de comprometimento com alguma informação.

${ }^{2}$ Tradução própria para o termo: Mittelfeld. 
ção entre rema e tema. Essa divisão funciona como limites verbais (sentence brackets). No exemplo abaixo hat e geschenk formam os limites na oração:

Der Großvater hat seinem Enkel ein Buch geschenk

Estes limites dividem os campos topológicos que são ocupados por outros constituintes da frase. As diferentes posições são: Vorfeld, que é o campo para a esquerda do limite; Mittelfeld o campo situado dentro dos limites da oração; Nachfeld localizado à direita do limite. Para possuir função modal, as partículas precisam seguir alguns critérios, incluindo a posição no campo central da oração. Dependendo da posição, do contexto, e também da intenção do emissor, o significado das PMs e logo, da oração, pode ser modificado, submetendo-se, desta forma, à intenção comunicativa desejada (AQUINO, 2016, p. 34).

Dentro de sua restrição topológica, as PMs podem transitar livremente no campo central, e este posicionamento na oração pode influenciar a interpretação e, consequentemente, a tradução destes elementos para o português. Assim, o significado expressivo das PMs é diretamente influenciado pelo contexto, mas as questões topológicas também devem ser ponderadas (MÖLLERING, 2001). Em vista disso, apresentamos neste trabalho, os resultados obtidos por meio de pesquisa processual em tradução, averiguando a interpretação da PM wohl considerando a sua disposição na oração e no contexto. ${ }^{3}$ Para tanto, foram aplicadas três tarefas de pós-edição (doravante PE) ${ }^{4}$, constituídas de três versões modificadas de um

\footnotetext{
${ }^{3}$ Vale ponderar que não é possível encontrar literatura relevante em tradução sobre a análise empírica do significado e funções pragmáticas das PMs dependendo do seu posicionamento em uma mesma sentença. Assim, esta pesquisa trás dados pioneiros com relação à investigação topológica da PM wohl e sua interpretação para o português brasileiro.

${ }^{4}$ A pós-edição representa a revisão de um texto traduzido por um sistema de tradução automática.
} 
mesmo texto, sendo que uma das orações continha a PM wohl em diferentes posições. Teve-se o intuito de observar o processamento e escolhas tradutórias de dois grupos de participantes (brasileiros e alemães) no momento da PE da PM wohl - em um texto em alemão traduzido automaticamente pelo Google Tradutor para o português - tendo em vista os posicionamentos deste elemento.

Com base na teoria da relevância (doravante TR) (SPERBER; WILSON, 1995, p.465) aplicada à tradução (GUTT, 1991), propomos investigar o esforço de processamento da PM wohl no par linguístico alemão/português, elucidando questões sobre a tradução de PMs para o português brasileiro. O princípio da relevância está baseado na relação de custo-benefício em que a cognição humana busca alcançar o maior efeito cognitivo através do menor esforço processual possível (SPERBER; WILSON, 1995, p. 465). Segundo GUTT (1991), a TR pode auxiliar a tradução no entendimento das operações mentais relacionadas ao processo de traduzir uma informação de uma língua para outra.

Nos termos relevantistas as PMs, se compreendidas e utilizadas adequadamente, podem gerar implicaturas fortes na busca de semelhança interpretativa e, por meio da capacidade metarrepresentativa proporcionam um elo entre os ambientes cognitivos dos indivíduos. Segundo a perspectiva de GUTT (2005), a metarrepresentação é alcançada via metarreflexão, ou seja, a capacidade que os seres humanos têm de representar como outra pessoa representa um estado de coisas. Dessa maneira, a metarrepresentação tem o intuito de reconstruir tanto os ambientes cognitivos do público-alvo do texto-fonte quanto os do público-alvo do texto-alvo.

Como as PMs fazem parte do ambiente cognitivo do falante de alemão, ele ou ela usam informações contextuais disponíveis em seu ambiente cognitivo para reconhecer imediatamente o significado pretendido, resultando em uma interpretação que alcance as expectativas de relevância, ou seja, uma relação adequada entre esforço e efeitos cognitivos (AQUINO, 2017, p. 82-83). Por outro lado, o processamento desses elementos pode ser mais custoso para o falante não nativo, pois essas informações contextuais não estão totalmente 
acessíveis em seus ambientes cognitivos. Não obstante, os resultados deste trabalho indicam que os participantes brasileiros alcançaram níveis adequados de efeitos contextuais no texto de chegada.

De qualquer forma, não se pode negar que as PMs representam elementos complexos da língua alemã, o que resulta em um grande desafio para a tradução, assim como para o ensino de línguas. Mas, por meio de uma análise focada nos aspectos contextuais e suas funções comunicativas nucleares, torna-se possível encontrar interpretações adequadas destes elementos para língua portuguesa. Portanto, este trabalho tem a intenção de observar, por meio do processamento de participantes brasileiros e alemães, a busca de semelhança interpretativa da PM wohl para o português brasileiro.

\section{Metodologia}

Retrataremos nesta seção os resultados de uma amostra de 16 participantes, 8 brasileiros e 8 alemães, dentre eles $37.5 \%$ do sexo feminino na faixa etária média de 29 anos de idade e, $62.5 \%$ do sexo masculino na média de 35 anos. Os participantes tinham conhecimento avançado em alemão e português como língua estrangeira (doravante LE), classificados como $\mathrm{C} 1$ até $\mathrm{C}^{5}$. Entre os participantes, $75 \%$ afirmaram possuir alguma experiência com tradução e $25 \%$ sem nenhuma experiência com tradução. No entanto, apenas $25 \%$ eram profissionais de tradução. Dente eles, $37.5 \%$ tinham experiência prévia com pós-edição, o restante adquiriu este conhecimento por meio do workshop oferecido pela pesquisadora.

O experimento foi constituído de três tarefas, contendo três versões de um mesmo texto jornalístico em alemão retirado do site Spiegel, traduzido pela máquina em português para então ser realizada a PE. O texto fonte em questão era intitulado Ich habe einen Menschen getötet contendo 62 palavras. Os participantes pós-editaram, por meio da ferramenta do Translog, o insumo da máquina

${ }^{5}$ Classificação de proficiência baseada em certificados de diferentes instituições. 
em português tendo acesso ao texto fonte original em alemão. Os dados de fixação ocular foram gravados durante a realização de cada tarefa e também no momento dos comentários nos protocolos verbais retrospectivos, isto é, após o final da tarefa.

Com o intuito de investigar a influência da posição da PM para a compreensão e PE destes elementos para o português, foram elaboradas três modificações no posicionamento de palavras em três orações no mesmo texto, sendo que tínhamos a intenção de observar especialmente o processamento da última frase com a PM wohl. Decidimos implementar modificações em todo o texto, além da oração com PM wohl, para não influenciar as decisões tradutórias, já que os participantes não tinham conhecimento sobre o tema de pesquisa. Mas, os participantes foram previamente informados que a coleta era referente a PE de três versões de um mesmo texto, a fim de investigar a diferença nas escolhas tradutórias, dependendo das posições lexicais.

A seguir, as imagens copiadas do programa Translog, na parte superior encontra-se o texto em alemão em três diferentes versões, e na parte inferior, as respectivas versões geradas pela tradução automática:

\section{Figura 1: Tarefa T1}

Utetret font Aign $A^{*}$ A

Vatthew Cordle verursachte einen tödlichen Unfall, ein 61-Jähriger starb. Der Polizei ist Jas bekannt, doch bisher wurde er nicht angeklagt. Nun hat der 22-Jährige alles jestanden. Auf YouTube. Staatsanwalt O'Brien sagte der Lokalzeitung es sei das 'überzeugendste Video", das er je gesehen habe. Er wird Cordle wohl am Montag wegen ahrlässiger Tötung anklagen.

Vatthew Cordle causou um acidente fatal, um menino de 61 anos de idade. A polícia ś conhecido, mas até agora ele não foi indiciado. Agora, a 22 anos de idade, zonfessou tudo. No YouTube. Procurador O'Brien disse ao jornal local que era o 'vídeo mais atraente", ele já tinha visto. Ele provavelmente vai acusar na segundaeira de homicídio involuntário Cordle.

Fonte: AQUINO (2016) 


\section{Figura 2: Tarefa T2}

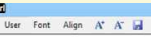

Matthew Cordle verursachte einen tödlichen Unfall, ein 61-Jähriger starb. Er wurde bisher nicht angeklagt, doch ist der Polizei das bekannt. Alles gestanden hat nun der 22-Jährige. Auf YouTube. Staatsanwalt O'Brien sagte der Lokalzeitung, es sei das "überzeugendste Video", das er je gesehen habe. Er wird wohl Cordle am Montag wegen fahrlässiger Tötung anklagen.

Matthew Cordle causou um acidente fatal, um menino de 61 anos de idade. Ele não foi acusado, mas a polícia familiar. Tudo tem sido agora a 22-year-old. No YouTube. Procurador O'Brien disse ao jornal local, que era o "vídeo mais atraente", ele já tinha visto. Ele provavelmente vai acusar Cordle na segundafeira de homicídio involuntário.

Fonte: AQUINO (2016)

\section{Figura 3: Tarefa T3}

tro

U.eet Font Align $A^{*} A^{A}$ 过

Matthew Cordle verursachte einen tödlichen Unfall, ein 61-Jähriger starb. Bisher wurde er nicht angeklagt, doch ist der Polizei das bekannt. Der 22-Jährige hat nun alles gestanden. Auf YouTube. Staatsanwalt O'Brien sagte der Lokalzeitung, es sei das "überzeugendste Video", das er je gesehen habe. Er wird Cordle am Montag wohl wegen fahrlässiger Tötung anklagen.

Matthew Cordle causou um acidente fatal, um menino de 61 anos de idade. Até agora ele não foi acusado, mas a polícia familiar. O jovem de 22 anos de idade, já confessou tudo. No YouTube. Procurador O'Brien disse ao jornal local, que era o "vídeo mais atraente", ele já tinha visto. Ele provavelmente vai acusar Cordle na segunda-feira de homicídio involuntário.

Fonte: AQUINO (2016)

A análise apresentada neste trabalho foi pautada por dados processuais relativos ao número e à duração das fixações gerados pelo rastreador ocular na área de interesse (doravante $\mathrm{AOI}$ ), isto é, na 
oração com PM wohl, na observação das mudanças e correções e pelos comentários nos protocolos (livre e guiados).

\section{Análise e resultado}

\subsection{As fixações oculares e o esforço de processamento}

Para analisar o esforço de processamento despendido nas três tarefas contendo a PM wohl em diferentes posições, apresentamse, na sequência, os gráficos 1,2 e 3 . O gráfico 1 mostra em segundos a média da duração por fixação dos dezesseis participantes nas três tarefas, para duas AOIs nos textos fonte e alvo (doravante TF e TA), e também com relação ao restante do texto, que foi usado como área de controle. Já os gráficos 2 e 3, apresentam os resultados de fixação na AOI e no restante do texto para os dois grupos de participantes, isto é, brasileiros e alemães. Estes resultados oferecem pistas sobre o esforço cognitivo despendido no processamento de orações com PM wohl em diferentes posições em um mesmo enunciado.

O gráfico 1 apresenta os resultados da duração média das fixações oculares nas AOI com a PM wohl, referente a todos os participantes nas três tarefas. 
Gráfico 1: Distribuição da duração média das fixações nas três tarefas para todos os participantes na AOI e restante do texto.

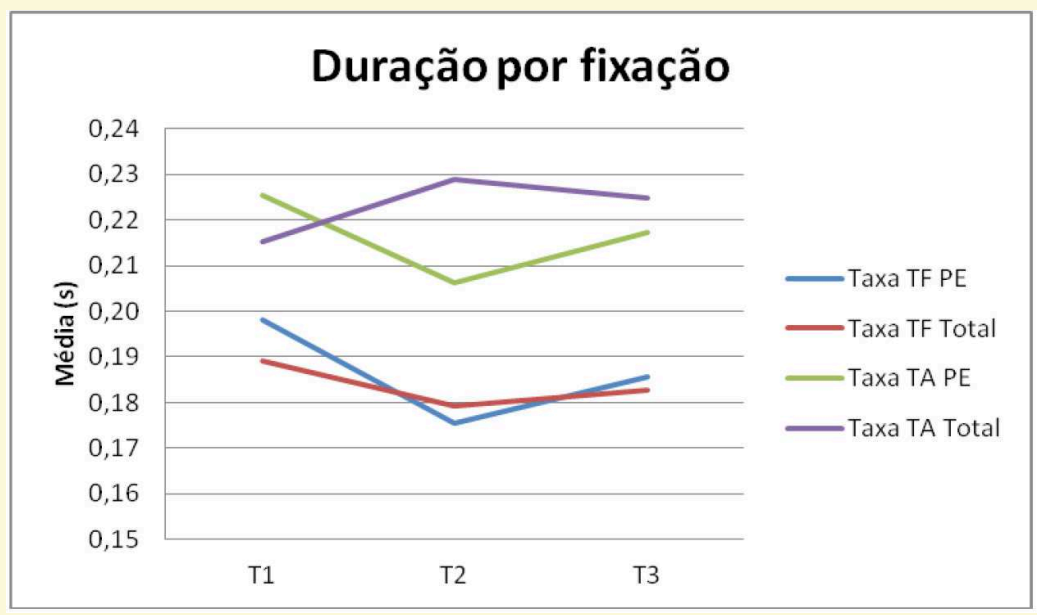

Fonte: AQUINO (2016)

Os resultados acima apontam para um maior esforço de processamento na AOI do TA em comparação ao TF. Este impacto no esforço de processamento advém da necessidade de novas inferências face ao insumo linguístico do tradutor automático. A análise estatística indica que tal diferença é estatisticamente significativa para $\mathrm{T} 2, \mathrm{t}(\mathrm{T} 2)=-2.336, \mathrm{p}=0.013$; e $\mathrm{T} 3, \mathrm{t}(\mathrm{T} 3)$ $=-1.479, \mathrm{p}=0.075$, e marginalmente significativa para a $\mathrm{T} 1$, $\mathrm{t}(\mathrm{T} 1)=-1.363, \mathrm{p}=0.09$. No TF, com exceção da T2, o esforço de processamento na AOI foi maior ao se comparar com o restante do texto. Já no TA, apenas em T1 observa-se um maior esforço de processamento na AOI. A diferença entre a AOI e o restante do texto não é estatisticamente significativa para todas as tarefas, indicando apenas uma tendência para um maior esforço em comparação à área de controle.

O esforço despendido na AOI da tarefa T1, tanto para o TF (197.97 ms; DP: $51.85 \mathrm{~ms}$ ), quanto para o TA (225.37 ms; DP: 
$72.05 \mathrm{~ms}$ ), possui a maior média de duração de fixação havendo um decaimento com o decorrer das tarefas. Este dado é compatível com os resultados encontrados na unidade de tradução e nos comentários retrospectivos. Os participantes sinalizaram ter gasto menos tempo nas tarefas, pois repetiram em T2 e T3 as edições realizadas na $\mathrm{T} 1$.

Os gráficos 2 e 3 apresentamos em segundos a média de duração das fixações acerca da AOI e o restante do texto, para os dos dois grupos de participantes (brasileiros e alemães).

Gráfico 2: Distribuição da duração média das fixações por tarefas para os participantes brasileiros e alemães para a AOI.

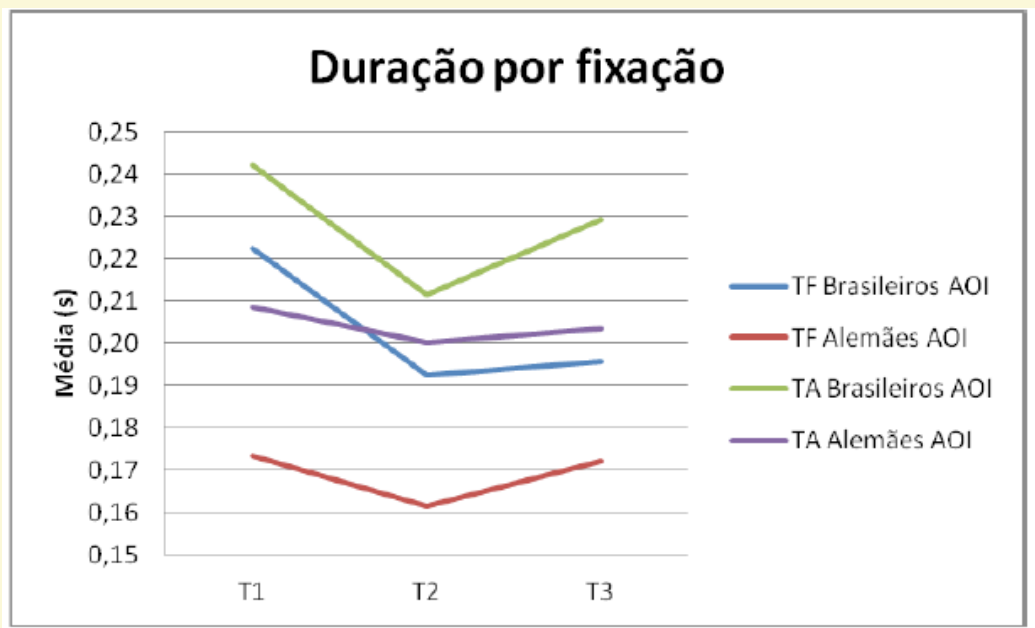

Fonte: AQUINO (2016) 
Gráfico 3: Distribuição da duração média das fixações por tarefas para os participantes brasileiros e alemães para o restante do texto.

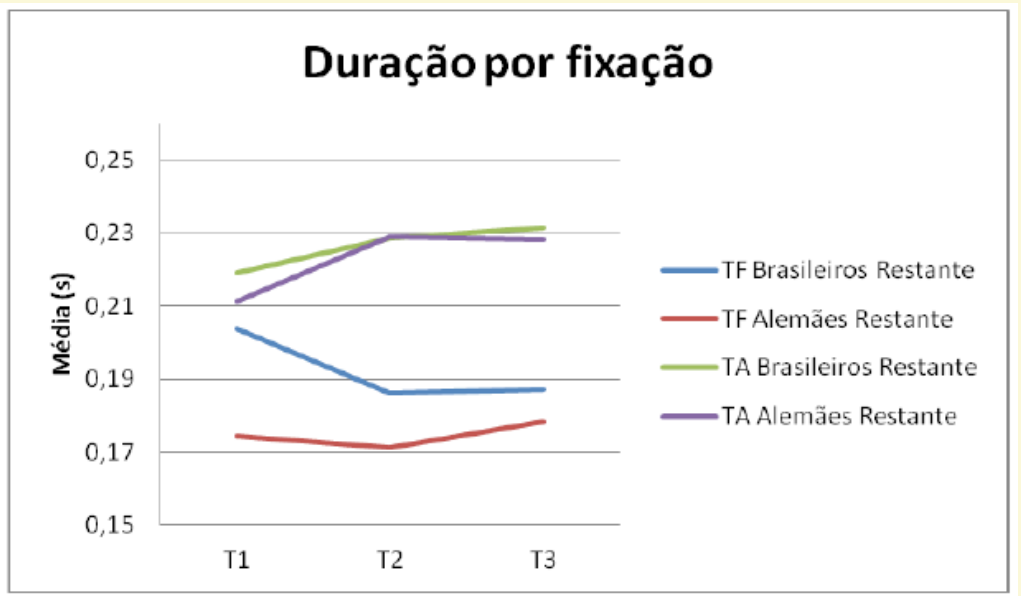

Fonte: AQUINO (2016)

Com relação à AOI - e também ao restante do texto - o grupo de alemães têm fixações menos duradoras do que os brasileiros em todas as tarefas, especialmente no TF. Essa averiguação é corroborada pela análise estatística que indica que a diferença na duração média de fixações entre brasileiros e alemães é significativa para o texto fonte na tarefa $\mathrm{T} 1(\mathrm{t}(\mathrm{T} 1)=2.089, \mathrm{p}=0.028)$ e, marginalmente significativa para $\mathrm{T} 2(\mathrm{t}(\mathrm{T} 2)=1.467, \mathrm{p}=0.089)$, enquanto para a T3 não é estatisticamente significativa $(\mathrm{t}(\mathrm{T} 3)=0.913, \mathrm{p}$ $=$ n.s.). Este resultado é compatível com as expectativas deste estudo e com os postulados da TR. Para os alemães a compreensão do significado e do uso das PMs é quase que imediata, isto é, os mecanismos mentais destes indivíduos tendem automaticamente a escolher estímulos potencialmente relevantes, reconhecendo então, as pistas comunicativas das PMs. Assim, pode-se afirmar que a identificação e processamento da PM wohl no TF requer um menor esforço de processamento dos alemães do que dos brasileiros. 
A respeito do texto alvo, a análise estatística revela que, tanto para a AOI $(\mathrm{t}(\mathrm{T} 1)=0.921, \mathrm{p}=\mathrm{n} . \mathrm{s} . ; \mathrm{t}(\mathrm{T} 2)=0.308, \mathrm{p}=\mathrm{n} . \mathrm{s}$.; $\mathrm{t}(\mathrm{T} 3)=0.814, \mathrm{p}=$ n.s. $)$, quanto para o restante do texto $(\mathrm{t}(\mathrm{T} 1)$ $=0.321, \mathrm{p}=$ n.s.; $\mathrm{t}(\mathrm{T} 2)=-0.019, \mathrm{p}=\mathrm{n} . \mathrm{s} . ; \mathrm{t}(\mathrm{T} 3)=0.481, \mathrm{p}$ $=$ n.s.), a diferença entre os dois grupos não é estatisticamente significativa. Deste modo, afigura-se que o esforço de processamento desta partícula, para a língua portuguesa em tarefas de PE, foi relativamente semelhante entre os dois grupos, apresentando, entretanto, um menor esforço por parte dos alemães. Neste sentido, observamos que o processo de representação mental da oração com PM exigiu um menor esforço cognitivo dos participantes alemães. Este resultado indica, entretanto, que a busca de semelhança interpretativa da função da PM wohl para outra língua, dentro de diferentes posições na frase, depende da metarepresentação ${ }^{6}$ das inferências proporcionadas pela PM em posições distintas e assim, a necessidade de interpretação de suas funções e intenções dependendo do enfoque semântico em cada oração.

A análise das fixações corrobora e completa os dados obtidos nos protocolos verbais. Nas próximas seções retratamos os comentários dos participantes com relação ao processo de PE da PM wohl nas três tarefas. Os resultados quantitativos e qualitativos, assim como as diferentes decisões tradutórias, oferecem pistas sobre a relação de esforço e efeitos contextuais resultantes do processamento das PMs em diferentes posições.

\subsection{Macrounidades de tradução e protocolos verbais retrospectivos}

Após a coleta de dados, os participantes realizaram dois protocolos verbais sobre o processo que acabaram de efetuar, com o uso

${ }^{6}$ Gutt $(2000,2005)$ define a tradução como um ato interpretativo interlingual que envolve a capacidade de metarepresentação, no qual o tradutor representa as informações do ambiente cognitivo do autor do texto de partida, para o público alvo do texto de chegada. 
da função replay do Translog, momento em que os tradutores tiveram a oportunidade de visualizar todo o processo realizado, para que então pudessem fazer os seus comentários com base naquilo que viam na tela. Os protocolos são instrumentos de coleta que possibilitam a recuperação de informações de natureza inferencial e processual, permitindo ao pesquisador tentar construir hipóteses baseadas em dados quantitativos.

No protocolo livre, os pós-editores foram estimulados a verbalizar suas reflexões sobre as diferentes etapas do processo de PE, comentando, entre outros aspectos, sobre a tomada de decisão e os problemas encontrados. No segundo protocolo, o guiado, responderam-se perguntas específicas sobre a AOI.

A análise das macrounidades permite observar as edições realizadas nas tarefas de PE. A seguir apresentamos, portanto, um panorama geral sobre as decisões tradutórias dos dois grupos de participantes acerca das três tarefas. O quadro a seguir indica as unidades de tradução dos 16 participantes brasileiros (B) e alemães (A) a respeito da AOI investigada. 
Quadro 1: Macro UTs produzidas nas T1, T2 e T3.

Unidade de Tradução T1

\begin{tabular}{|c|c|}
\hline P1_B & $\begin{array}{l}\text { Provavelmente, irá acusar Cordle de } \\
\text { homicídio }\end{array}$ \\
\hline P2_A & $\begin{array}{l}\text { Ele provavelmente vai acusar Cordle na } \\
\text { segunda-feira }\end{array}$ \\
\hline P3_A & Ele provavelmente vai acusar Cordle \\
\hline P4_B & $\begin{array}{l}\text { Ele provavelmente vai indicaiar Cordle por } \\
\text { homicídio }\end{array}$ \\
\hline P5_B & Ele acusará Cordle na segunda-feira \\
\hline P6_A & $\begin{array}{l}\text { Provavelmente ele vai acusar Cordle na } \\
\text { segunda-feira }\end{array}$ \\
\hline P7_B & $\begin{array}{l}\text { Ele provavelmente vai acusar Cordle de } \\
\text { homicidio }\end{array}$ \\
\hline P8_A & $\begin{array}{l}\text { Ele provavelmente vai acusar Cordle na } \\
\text { segunda-feira }\end{array}$ \\
\hline P9_A & $\begin{array}{l}\text { Ele provavelmente vai acusar Cordle na } \\
\text { segunda-feira }\end{array}$ \\
\hline P10_B & $\begin{array}{l}\text { Ele provavelmente vai acusar Cordle de } \\
\text { homicídio }\end{array}$ \\
\hline P11_B & $\begin{array}{l}\text { Ele provavelmente vai acusar Cordle de } \\
\text { homicídio }\end{array}$ \\
\hline P12_A & $\begin{array}{l}\text { Ele provavelmente vai acusar na Cordle } \\
\text { segunda-feira }\end{array}$ \\
\hline P13_B & $\begin{array}{l}\text { Ele provavelmente vai acusar Cordle na } \\
\text { segunda-feira }\end{array}$ \\
\hline P14_A & $\begin{array}{l}\text { Ele provavelmente vai acusar Cordle na } \\
\text { segunda-feira }\end{array}$ \\
\hline P15_B & $\begin{array}{l}\text { Ele tem a intenção de acusar Cordle na } \\
\text { segunda-feira }\end{array}$ \\
\hline P16_A & $\begin{array}{l}\text { Na próxima segunda-feira, ele } \\
\text { provavelmente vá acusar Cordle }\end{array}$ \\
\hline
\end{tabular}

Unidade de Tradução T2

Unidade de Tradução T3

\begin{tabular}{|c|c|}
\hline $\begin{array}{l}\text { Ele provavelmente vai acusar Cordle na } \\
\text { segunda-feira }\end{array}$ & $\begin{array}{l}\text { Ele provavelmente irá acusar Cordle de } \\
\text { homicídio }\end{array}$ \\
\hline $\begin{array}{l}\text { Ele provavelmente vai acusar Cordle na } \\
\text { segunda-feira }\end{array}$ & $\begin{array}{l}\text { Ele provavelmente vai acusar Cordle na } \\
\text { segunda-feira }\end{array}$ \\
\hline $\begin{array}{l}\text { Ele provavelmente vai acusar Cordle na } \\
\text { segunda-feira }\end{array}$ & $\begin{array}{l}\text { Ele provavelmente vai acusar Cordle na } \\
\text { segunda-feira }\end{array}$ \\
\hline $\begin{array}{l}\text { Ele provavelmente vai acusar Cordle na } \\
\text { segunda-feira }\end{array}$ & Ele deve acusar Cordle na segunda-feira \\
\hline $\begin{array}{l}\text { Ele provavelmente vai acusar Cordle na } \\
\text { segunda-feira }\end{array}$ & $\begin{array}{l}\text { Ele provavelmente vai indiciar Cordle na } \\
\text { segunda-feira }\end{array}$ \\
\hline $\begin{array}{l}\text { Ele provavelmente vai acusar Cordle na } \\
\text { segunda-feira }\end{array}$ & $\begin{array}{l}\text { Ele provavelmente vai acusar Cordle na } \\
\text { segunda-feira }\end{array}$ \\
\hline $\begin{array}{l}\text { Ele provavelmente vai acusar Cordle na } \\
\text { segunda-feira }\end{array}$ & $\begin{array}{l}\text { Ele provavelmente vai acusar Cordle na } \\
\text { segunda-feira }\end{array}$ \\
\hline $\begin{array}{l}\text { Ele provavelmente vai acusar Cordle na } \\
\text { segunda-feira }\end{array}$ & $\begin{array}{l}\text { Ele provavelmente vai acusar Cordle na } \\
\text { segunda-feira }\end{array}$ \\
\hline $\begin{array}{l}\text { Ele provavelmente vai acusar Cordle na } \\
\text { segunda-feira }\end{array}$ & $\begin{array}{l}\text { Ele provavelmente vai acusar Cordle na } \\
\text { segunda-feira }\end{array}$ \\
\hline $\begin{array}{l}\text { Ele provavelmente vai acusar Cordle na } \\
\text { segunda-feira }\end{array}$ & $\begin{array}{l}\text { Ele provavelmente vai acusar Cordle na } \\
\text { segunda-feira }\end{array}$ \\
\hline $\begin{array}{l}\text { Ele provavelmente vai acusar Cordle na } \\
\text { segunda-feira }\end{array}$ & Ele deve acusar Cordle na segunda-feira \\
\hline $\begin{array}{l}\text { Ele provavelmente vai acusar Cordle na } \\
\text { segunda-feira }\end{array}$ & $\begin{array}{l}\text { Na segunda-feira, ele provavelmente vai } \\
\text { acusar Cordle }\end{array}$ \\
\hline $\begin{array}{l}\text { Ele provavelmente vai acusar Cordle na } \\
\text { segunda-feira }\end{array}$ & $\begin{array}{l}\text { Ele provavelmente vai acusar Cordle na } \\
\text { segunda-feira }\end{array}$ \\
\hline $\begin{array}{l}\text { Ele provavelmente vai acusar Cordle na } \\
\text { segunda-feira }\end{array}$ & $\begin{array}{l}\text { Ele provavelmente vai acusar Cordle na } \\
\text { segunda-feira }\end{array}$ \\
\hline Ele pretende acusar Cordle na segunda-feira & Ele pretende acusar Cordle na segunda-feira \\
\hline $\begin{array}{l}\text { Na próxima segunda-feira, ele } \\
\text { provavelmente vai acusar Cordle }\end{array}$ & $\begin{array}{l}\text { Na próxima segunda-feira, ele } \\
\text { provavelmente vá acusarCordle }\end{array}$ \\
\hline
\end{tabular}

Ele provavelmente vai acusar Cordle n

Ele provavelmente vai acusar Cordle na

segunda-feira

Ele provavelmente vai acusar Cordle na segunda-feira

le provavelmente vai acusar Cordle na a-feira segunda-feira

le provavelmente vai acusar Cordle na

segunda-feir

le provavelmente vai acusar Cordle na

segunda-feira

segunda-feira provavelmente vai acusar Cordle

Fonte: AQUINO (2016)

Os dados demonstram que os participantes mantiveram as edições curtas, voltadas apenas a questões gramaticais, lexicais e de ordem da frase. O pouco esforço empreendido neste processo revela uma retextualização, que não recupera os efeitos contextuais almejados pelo texto de partida. Consequentemente, a maioria das edições não chega a alcançar efeitos contextuais satisfatórios.

$\mathrm{Na}$ tarefa de PE, essa escolha emerge a partir da interação com o insumo do sistema de TA, a partir da qual os pós-editores são compelidos a derivar as implicaturas e recriar, no texto de chegada, os efeitos cognitivos produzidos no contexto de partida. Desse modo, a construção da semelhança interpretativa no processo de PE estaria atrelada à recriação do conceito veiculado na língua de 
partida e enunciados de origem dupla: texto fonte e texto traduzido automaticamente. Entretanto, neste experimento, a maioria das edições não apresentou soluções diretas para a compreensão de wohl no contexto. Mesmo com a diferença entre as três versões da tarefa, os participantes pareceram ter optado por manter o insumo da máquina e não interpretar as PMs dentro do contexto específico em que se encontravam em cada versão.

A homogeneidade na tomada de decisão pode ser explicada por alguns motivos: falta de atenção às mudanças realizadas na posição; falta de experiência em interpretar as PMs para outras línguas; satisfação com o insumo da máquina. Ainda, é possível questionar se em um processo tradutório este resultado fosse diferente, já que, nos protocolos alguns participantes comentaram que se a tradução fosse feita inteiramente por eles as decisões tradutórias seriam outras.

Todavia, no momento dos protocolos verbais, quando os participantes tiveram acesso às três versões do texto fonte juntas, e das edições que haviam feito, foi possível obter dados relevantes com relação ao processamento e reflexão das tarefas. A realização dos relatos permitiu comentários focados no significado, na dependência do contexto e da posição para encontrar uma semelhança interpretativa destes elementos no português.

Os dados dos relatos retrospectivos foram coletados após a conclusão das tarefas de PE com o recurso da função replay ${ }^{7}$ do Translog. O primeiro quadro introduz os principais temas apontados pelos participantes sobre o processamento das AOI com a PM wohl nas três versões dos textos. O segundo quadro resume, em porcentagem, a diferença de respostas entre os participantes alemães e brasileiros.

${ }^{7}$ Com esta função os tradutores têm a oportunidade de visualizar todo o processo que acabaram de realizar, para que pudessem fazer os seus comentários se baseando naquilo que viam na tela. 
Quadro 2: Temas principais mencionados no protocolo verbal (livre e guiado) nas três tarefas.

\begin{tabular}{|c|c|c|c|c|c|c|c|c|c|}
\hline & $\begin{array}{c}\text { Dificuldade de } \\
\text { compreensão }\end{array}$ & $\begin{array}{c}\text { MT } \\
\text { aceito }\end{array}$ & $\begin{array}{c}\text { Sem mudanças } \\
\text { ou não notou } \\
\text { diferença }\end{array}$ & $\begin{array}{c}\text { Notou } \\
\text { diferença } \\
\text { (Depois) }\end{array}$ & Contexto & $\begin{array}{c}\text { Posição } \\
\text { não } \\
\text { importa }\end{array}$ & $\begin{array}{c}\text { Posiçao } \\
\text { muda } \\
\text { significado }\end{array}$ & $\begin{array}{c}\text { Sem } \\
\text { tradução }\end{array}$ & $\begin{array}{c}\text { Wohl } \\
\text { oferece } \\
\text { ênfase }\end{array}$ \\
\hline P1 & $\mathrm{X}$ & $\mathrm{X}$ & $\mathrm{X}$ & $\mathrm{X}$ & & & & & \\
\hline P2 & & $\mathrm{X}$ & & $\mathrm{X}$ & & & & & \\
\hline P3 & & $\mathrm{X}$ & & & & $\mathrm{X}$ & & $\mathrm{X}$ & \\
\hline P4 & $\mathrm{X}$ & & & & & $\mathrm{X}$ & & $\mathrm{X}$ & $\mathrm{X}$ \\
\hline P5 & $\mathrm{X}$ & & & $\mathrm{X}$ & & $\mathrm{X}$ & & $\mathrm{X}$ \\
\hline P6 & & $\mathrm{X}$ & & $\mathrm{X}$ & & & & & $\mathrm{X}$ \\
\hline P7 & $\mathrm{X}$ & $\mathrm{X}$ & & $\mathrm{X}$ & $\mathrm{X}$ & & $\mathrm{X}$ & \\
\hline P8 & & $\mathrm{X}$ & $\mathrm{X}$ & & & $\mathrm{X}$ & & & \\
\hline P9 & & $\mathrm{X}$ & & $\mathrm{X}$ & & $\mathrm{X}$ & & $\mathrm{X}$ \\
\hline P10 & $\mathrm{X}$ & $\mathrm{X}$ & $\mathrm{X}$ & & & & $\mathrm{X}$ & \\
\hline P11 & $\mathrm{X}$ & & $\mathrm{X}$ & & & & $\mathrm{X}$ & \\
\hline P12 & & $\mathrm{X}$ & $\mathrm{X}$ & $\mathrm{X}$ & & & & $\mathrm{X}$ \\
\hline P13 & $\mathrm{X}$ & $\mathrm{X}$ & $\mathrm{X}$ & $\mathrm{X}$ & & & $\mathrm{X}$ & $\mathrm{X}$ \\
\hline P14 & & $\mathrm{X}$ & & & & & $\mathrm{X}$ & $\mathrm{X}$ \\
\hline P15 & $\mathrm{X}$ & & $\mathrm{X}$ & $\mathrm{X}$ & $\mathrm{X}$ & & $\mathrm{X}$ & $\mathrm{X}$ \\
\hline P16 & & $\mathrm{X}$ & $\mathrm{X}$ & $\mathrm{X}$ & & $\mathrm{X}$ & & $\mathrm{X}$ \\
\hline
\end{tabular}

Fonte: AQUINO (2016)

Quadro 3: Frequência dos temas principais mencionados no protocolo verbal (livre e guiado) nas três tarefas

\begin{tabular}{|c|c|c|c|c|c|c|c|c|c|}
\hline & $\begin{array}{c}\text { Dificuldade de } \\
\text { compreensão }\end{array}$ & $\begin{array}{c}\text { MT } \\
\text { aceito }\end{array}$ & $\begin{array}{c}\text { Sem mudanças } \\
\text { ou não notou } \\
\text { diferença }\end{array}$ & $\begin{array}{c}\text { Notou } \\
\text { diferença } \\
\text { (Depois) }\end{array}$ & Contexto & $\begin{array}{c}\text { Posição } \\
\text { não } \\
\text { importa }\end{array}$ & $\begin{array}{c}\text { Posiçao } \\
\text { muda } \\
\text { significado }\end{array}$ & $\begin{array}{c}\text { Sem } \\
\text { tradução }\end{array}$ & $\begin{array}{c}\text { Wohl } \\
\text { oferece } \\
\text { ênfase }\end{array}$ \\
\hline $\mathbf{A}$ & $0 \%$ & $100 \%$ & $25 \%$ & $62,5 \%$ & $0 \%$ & $50 \%$ & $12,5 \%$ & $62,5 \%$ & $25 \%$ \\
\hline B & $100 \%$ & $50 \%$ & $62,5 \%$ & $62,5 \%$ & $25 \%$ & $25 \%$ & $62,5 \%$ & $37,5 \%$ & $75 \%$ \\
\hline
\end{tabular}

Fonte: AQUINO (2016)

Durante as verbalizações os participantes fizeram alusão aos problemas de acessibilidade contextual da informação veiculada pelas tarefas, oferecendo indicações sobre as decisões tradutórias e o processamento da PM wohl em diferentes posições. Ainda que os temas fossem recorrentes em ambos os grupos, o tipo de informa- 
ção oferecida pelos participantes foi bastante distinto, especialmente acerca das funções comunicativas de wohl, tanto para o TF em alemão, como para a interpretação para o português.

Abaixo podemos examinar alguns exemplos de relatos com relação ao processamento de wohl:

P01_(B): “O significado de wohl não é claro para mim. Aceitei a tradução e não alterei a ordem. Eu poderia traduzir o primeiro provavelmente com segunda-feira. Comparando as três versões na tela consigo ver a diferença que deveria ter feito".

P04_(B): "Nas mudanças depende do que você quer focar na frase. Dá uma ênfase diferente no tempo ou ação. É bastante flexível e não atrapalha a compreensão".

P15_(B): "Olha não percebi, mas muda mesmo dependendo da posição. Usa wohl antes de Montag, dando a sensação que é um final de semana e ele tem pressa, então vai acusar na segunda. Para mim significa que ele vai fazer sim, sem dúvida, vai acusar. Na terceira a atenção passa para o caráter do crime. Acho que as três versões são diferentes, mas com uma diferença bem pequena para quem não é nativo".

Como é possível observar, os participantes brasileiros comentaram sobre a função de wohl dependendo da sua colocação na frase. Eles refletiram sobre suas decisões tradutórias no processamento do texto, buscando efeitos contextuais, mesmo que depois da realização da tarefa. Segundo os dados registrados no protocolo, muitos alemães não viram a necessidade de processar wohl diferentemente dependendo da posição na oração, no entanto, não justificaram a sua interpretação. A explicação mais recorrente foi a impossibilidade de traduzir as PMs para o português, por isso aceitaram o insumo da máquina ou omitiram wohl da frase: 
P03_(A): "Para mim a posição de wohl não muda nada em português, fica igual".

P09_(A): “A terceira versão é quase igual a primeira, só me perguntei se provavelmente seria a melhor tradução, mas não sabia então deixei. Em português eu acho que a tradução não tem diferença no significado".

P14_(A): “A tradução como provavelmente me ajudou. Estando provavelmente não tem diferença na tradução a ordem".

Como discutimos anteriormente, estes resultados foram contra as expectativas iniciais deste trabalho, pois, como a implicatura das PMs faz parte do ambiente cognitivo dos nativos, esperava-se que as edições e comentários buscassem aumentar os níveis contextuais para o texto alvo em português. No entanto, ainda que representando esta informação para si, os alemães não conseguiram acessar o ambiente cognitivo de leitores do texto de chegada. Mesmo sem a tendência imediata de identificar a função das PMs, os brasileiros foram capazes de interpretar a AOI do TF para o TA de maneira relevante, ou seja, buscando semelhanças interpretativas capazes de gerar efeitos contextuais.

As verbalizações corroborar os resultados de fixação ocular e as edições feitas no Translog. Os alemães gastaram menor esforço cognitivo para processar e compreender as PMs em alemão, não obstante, apenas o grupo dos brasileiros buscou uma relação de esforço efeito positivas. Como resultado, os alemães aceitaram a opção da máquina seja por falta de opção, ou por falta de conhecimento prévio a respeito da língua e cultura brasileira.

A investigação deste experimento contribui com informações relevantes e interessantes quanto ao processo da PM wohl de brasileiros e alemães. Os resultados encontrados provocaram novas re- 
flexões sobre a diferença entre estes grupos quanto à compreensão e interpretação das PMs para o português.

\section{Conclusão}

Esta pesquisa se propôs, com base nos postulados relevantistas, a investigar o esforço de processamento e decisões tradutórias durante a PE da PM wohl em diferentes posições em uma mesma oração. Para tal fim, realizou-se um experimento em que a duração e número de fixações oculares de participantes brasileiros e alemães na AOI contendo a PM wohl puderam ser medidas.

Os relatos obtidos no protocolo verbal retrospectivo auxiliaram a análise e compreensão dos dados de fixação ocular e decisões tradutórias. Segundo os dados de fixação, os participantes alemães despenderam um menor esforço cognitivo para processar a PM wohl. No momento da reflexão sobre o seu processo de edição, estes participantes justificaram apenas a recontextualização do texto, não fazendo alusão aos problemas de acessibilidade contextual da informação veiculada pelo texto de partida. Já os participantes brasileiros demonstraram maior capacidade metarepresentativa ao interpretarem as informações do ambiente cognitivo do texto de partida contendo a PM, para o texto de chegada em português, buscando efeitos contextuais adequados à tarefa que realizaram.

Logo, a relação de esforço e efeito apresentou resultados diferenciados entre os dois grupos, o que indica que em ambientes cognitivos diferenciados, as implicações na atribuição do mínimo esforço cognitivo necessário, para alcançar um determinado efeito contextual são distintas. A capacidade de metarepresentação de cada indivíduo determina a quantidade de esforço a ser despendida para a recriação da intenção comunicativa. Assim, embora a TR postule que a compreensão do significado implica uma relação de equilíbrio entre menor esforço para gerar o máximo possível de efeitos cognitivos, constatamos que existem, de fato, outras possi- 
bilidades de interação. Essas possibilidades variam em função do propósito comunicativo e dos indivíduos envolvidos no processo.

Com relação à investigação das PMs em diferentes posições, pode-se verificar que, quando processadas adequadamente, além do contexto, a colocação na oração influencia na busca de significado e semelhança interpretativa para o português. De fato, as modificações de posições da PM wohl ofereciam diferentes ênfases na oração, influenciando diretamente na tradução para o português. Não obstante, a função nuclear da partícula permanece, evidenciando que o conhecimento das questões semânticas das PMs pode solucionar possíveis dificuldades de compreensão, tradução e ensino destes elementos.

Ainda, os resultados obtidos nesta pesquisa indicam que se interpretadas de maneira eficaz, as PMs podem gerar um grande efeito cognitivo, adquirindo a função de pistas comunicativas necessárias para a troca entre ambientes cognitivos. Pela complexidade do processo inferencial envolvendo as PMs e a importância para a relação social e comunicativa em língua alemã, a sua análise deve essencialmente levar em consideração diferentes aspectos, como o contexto, a função comunicativa núcleo, as intenções e expectativas dos interlocutores (AQUINO, 2017, p. 177).

Por fim, cabe salientar que este trabalho vem contribuir para a pesquisa na área de estudos da tradução e linguística aplicada, uma vez que apresenta uma nova perspectiva sobre o processamento e função comunicativa da PM wohl. Ademais, faz-se premente enfatizar a necessidade de ampliar o número de estudos empíricos com foco nos processos cognitivos das PMs, especialmente a busca de amostras de partículas e participantes maiores, além de comparar o processamento da PE com o da tradução. 


\section{Referências}

ABRAHAM, Werner. Introduction. In: ABRAHAM, Werner (Ed.). Discourse particles. Descriptive and theoretical investigations on the logical, syntactic, and pragmatic properties of discourse particles in German. Amsterdam: John Benjamins, 1991a. p. 1-10.

ABRAHAM, Werner. Discourse Particles in German: How does their illocutive force come about? In: ABRAHAM, Werner (Ed.). Discourse particles. Descriptive and theoretical investigations on the logical, syntactic, and pragmatic properties of discourse particles in German. Amsterdam: Benjamins, 1991b. p. 203-252.

ABRAHAM, Werner. Sprecherdeixis und Merkmaldistributionsdifferential deutscher Modalitätselemente. Deutsche Sprache: Zeitschrift für Theorie, Praxis, Dokumentation, Berlin, v. 40, n. 1, p. 72-95, 2012.

AQUINO, Marceli. A força comunicativa das partículas modais alemãs no ensino de línguas. Diálogo das Letras, Pau dos Ferros, v. 1, n. 2, p. 103-115, 2012.

AQUINO, Marceli. O esforço de processamento das partículas modais doch e wohl em tarefas de pós-edição: uma investigação processual no par linguístico alemão/português. Tese (Doutorado em Estudos Linguísticos) Faculdade de Letras, Universidade Federal de Minas Gerais, Belo Horizonte, 2016.

AQUINO, Marceli. O processamento das partículas modais alemãs em tarefas de pós-edição. Pandaemonium Germanicum, São Paulo, v. 20, n. 30, p. 65-85, 2017.

AQUINO, Marceli. O questionário como ferramenta no ensino de partículas modais alemãs. Pandaemonium Germanicum, São Paulo, v. 20, n. 30, p. 65-85, 2017.

GUTT, Ernst-August. Translation and relevance: cognition and context. Cambridge: Blackwell, 1991.

GUTT, Ernst-August. Translation and relevance: cognition and context. $2^{\text {nd }} e d$. Manchester: St. Jerome, 2000. 
GUTT, Ernst-August. Challenges of metarepresentation to translation competence. In: FLEISCHMANN, Eberhard; SCHMITT, Peter A.; WOTJAK, Gerd (Ed.). Tagungsberichte der LICTRA (Leipzig International Conference on Translation Studies). Tübingen: Stauffenberg, 2005. p. 77-89.

HELBIG, Gerhard. Lexikon deutscher Partikeln. 2. ed. Leipzig: Enzyklopädie, 1990.

LEISS, Elisabeth. Epistemicity, evidentiality, and Theory of Mind (ToM). In: ABRAHAM, Werner; LEISS, Elisabeth (Ed.). Modality and theory of mind: elements across languages. Berlin: De Gruyter, 2012. p. 37-66.

MÖLLERING, Martina. Teaching German modal particles: a corpus-based approach. Language, Learning \& Technology, v. 5, n. 3, p. 130-151, 2001.

SPERBER, Dan; WILSON, Deirdre. Relevance: communication and cognition. 2. ed. Oxford (UK): Blackwell, 1995.

SPERBER, Dan; WILSON, Deirdre. Teoria da Relevância. Linguagem em (Dis) curso, Tubarão, v. 5, número especial, p. 221-268, 2005.

THURMAIR, Maria. Modalpartikeln und ihre Kombinationen. Tübingen: Niemeyer, 1989. (Linguistische Arbeiten, 223).

ZIMMERMANN, Malte. Zum Wohl: Diskurspartikeln als Satztypmodifikatoren. Linguistische Berichte 199, p. 253-286, 2004.

ZIMMERMANN, Malte. Contrastive Focus and Emphasis. Acta Linguistica Hungarica 55, p. 347-360, 2008.

Recebido em: 02/04/2018

Aceito em: 07/07/2018

Publicado em setembro de 2018

Marceli Aquino. E-mail: marceli.c.aquino@gmail.com

ORCID: https://orcid.org/0000-0003-0518-7639 